\title{
Kinetics of enteroendocrine cells with implications for their origin: a study of the cholecystokinin and gastrin subpopulations combining tritiated thymidine labelling with immunocytochemistry in the mouse
}

\author{
E M Thompson, Y E Price, N A Wright
}

\begin{abstract}
Evidence for a common endodermal stem cell has been derived from kinetic studies in mouse small intestine which indicate that the turnover characteristics of endocrine cells are similar to those of other cell lineages (columnar and goblet cells). We have used continuous tritiated thymidine labelling and peptide immunocytochemistry on resin embedded semithin sections, a combination of techniques which have not been used before in the small intestine. Our data show that the turnover time for endocrine cells in the small intestine is $\mathbf{1 0}$ days, considerably longer than the four days suggested by previous studies, although for columnar and mucous cell lineages, turnover rates are similar to the published literature. In the stomach, the turnover time was very slow indeed (of the order of 45-60 days). These results show that endocrine cells do not share turnover characteristics with the other cell types and suggest that they constitute a kinetically distinct cell population independent of the other cell lineages. These data are not consistent with a common stem cell origin for gut endocrine cells.
\end{abstract}

There has been considerable controversy as to the origin of endocrine cells for much of this century. Current thought favours a local origin for a common endodermal stem cell, although the modified neural crest theory of Pearse ${ }^{1}$ which postulates a specific stem cell pool of 'neuroendocrine-programmed' cells derived from primitive epiblast has not been disproved.

In a study of continuous tritiated thymidine labelling followed by autoradiography on ultrathin sections, Cheng and Leblond ${ }^{2+}$ found that in murine small bowel, the turnover time for columnar, mucous, and enteroendocrine cells was similar. Labelling first appeared in the lower part of the crypts in columnar cells which were thought to be stem cells, with labelling in differentiated cell lineages appearing later. They also showed that columnar, mucous and enteroendocrine cells migrated up on to the villi together. These authors argued that similar kinetic characteristics of the different cell lineages suggested a common stem cell origin, with multipotential stem cells housed in specific stem cell zones. Although several other studies have been done, most can be criticised on technical grounds. For instance, Odartchenko et $a l^{5}$ and Inokuchi $e t a l^{6}$ both used sections 3-4 $\mu$ thick which are unsuitable for accurate autoradiography because deep seated electrons do not reach the photographic film and also because it is easy to mistakenly assume that a nucleus belongs to cytoplasm which is merely superimposed. ${ }^{7}$ The methods of identifying endocrine cell populations have also been less specific. Cheng and Leblond ${ }^{2-4}$ identified endocrine cells by the presence of neurosecretory granules on their sections. Odartchenko et $a l^{5}$ and Deschner and Lipkin ${ }^{8}$ used diazo stains. The latter used projections of the labelling curve following a single dose of tritiated thymidine rather than a continuous labelling experiment, a notoriously inaccurate method, probably because of dilution of the label through division of the labelled cells. ${ }^{9}$ Some authors have also used silver stains to identify endocrine cells. ${ }^{10}$

The aim of this study was to do a kinetic experiment using immunocytochemistry to identify specific endocrine cell subpopulations combined with autoradiography on semithin resin embedded sections, $1 \mu \mathrm{m}$ thick, in order to see whether specifically identified endocrine cells do share similar turnover times for the other cell lineages.

\section{Methods}

ANIMALS

$\mathrm{Balb} / \mathrm{C}$ female mice were used for all experiments. They were housed in cages of six in constant temperature conditions with free access to food and water. In experiments 1 and 2 they were approximately $30 \mathrm{~g}$ in weight, whereas those in experiment 3 weighed approximately $20 \mathrm{~g}$.

TRITIATED THYMIDINE

This was obtained from Amersham International and had a specific activity of $5 \mathrm{Ci} / \mathrm{mmol}$.

PROCEDURE

Injections of tritiated thymidine were given intraperitoneally in a dose of $0.5 \mathrm{uCi} / \mathrm{g}$. Animals were killed by cervical dislocation.

\section{Experiment 1 flash labelling experiment}

Six mice were killed one hour after one injection of tritiated thymidine. 
TABLE I Absorption controls

\begin{tabular}{|c|c|c|c|c|c|c|c|c|c|c|c|}
\hline \multirow{2}{*}{\multicolumn{2}{|c|}{$\begin{array}{l}\text { Antibody peptide } \\
\text { to }\end{array}$}} & \multicolumn{8}{|c|}{ Peptide concentration $(\mathrm{nmol} / \mathrm{ml})$} & \multirow{2}{*}{$\begin{array}{l}\text { Antibody } \\
\text { alone }\end{array}$} & \multirow{2}{*}{$\begin{array}{l}\text { Positive } \\
\text { control }\end{array}$} \\
\hline & & 10 & 5 & $l$ & $0 \cdot 1$ & 0.01 & 0.001 & 0.0001 & 0.00001 & & \\
\hline SHT & $5 \mathrm{HT}$ & - & - & - & - & - & + & + & & + & + \\
\hline \multirow{3}{*}{ Gastrin/ } & /Gastrin & - & + & + & + & + & + & + & + & + & + \\
\hline & $\mathrm{CCK}_{8}$ & - & - & - & - & - & - & - & + & & \\
\hline & $\mathrm{CCK}_{33}$ & - & - & - & - & - & - & $-(9)$ & + & & \\
\hline
\end{tabular}

Experiment 2 four day continuous labelling experiment

Starting off with 20 mice, each mouse was injected with tritiated thymidine every six hours. One mouse was killed one hour after each injection and the experiment was terminated after 96 hours.

\section{Experiment 3 eight day continuous labelling experiment}

Thirty mice were injected with tritiated thymidine every six hours and one animal killed an hour after each injection. The experiment finished after 192 hours.

\section{FIXATION AND EMBEDDING}

Pieces of jejunum and longitudinal strips of stomach were fixed in $2.5 \%$ glutaraldehyde for experiments 1 and 2. For experiment 3, Karnovsky's fixative with $2 \cdot 0 \%$ formalin and $0.5 \%$ glutaraldehyde was used.

All tissue subsequently embedded in Araldite. Fifty sequential $1 \mu \mathrm{m}$ sections were cut on water boats on a Reichert-Jung Autocut microtome. Every fifth section was put into one of five water baths so that 10 sections cut at $5 \mu \mathrm{m}$ intervals could be mounted on each five glass slides.

\section{IMMUNOSTAINING}

The resin was removed with a saturated solution of ethanolic sodium hydroxide for 30 minutes and the slides were rehydrated through $90 \%$, $70 \%$, and $50 \%$ ethanol to water. Endogenous peroxidase was blocked with hydrogen peroxide $0.3 \%$ for 30 minutes, and after rinsing in phosphate buffered saline (PBS), non-specific immunoglobulin binding was blocked with normal swine serum 1:20 for 10 minutes. The primary antibodies used were polyclonal rabbit antibodies to swine 5hydroxytryptamine (5HT) (664) and cholecystokinin (1199), and were kindly donated by Professor J Polak. Both were used at 1:5000 dilution, this having been found to be the optimal dilution for good staining without background in a series of doubling dilutions, and were incubated at $4^{\circ} \mathrm{C}$ overnight. After washing three times in PBS, swine antirabbit antibody (Dakopatts) was applied at 1:200 dilution for $\mathbf{3 0}$ minutes. After three more washes in PBS, the slides were incubated with rabbit peroxidase-antiperoxidase (Miles Scientific) at 1:300 dilution for 30 minutes and then washed again. The peroxidase binding was demonstrated by oxidation of diaminobenzidine $0.025 \%$ (Aldrich Chemical Co), in the presence of hydrogen peroxide $0.03 \%$ for five minutes. Normal rabbit serum was used as a negative control (1:1000) and pig jejunum was used as a positive control section for both antibodies. Cross absorption studies for gastrin/ cholecystokinin (CCK) were done on the gastrin/ CCK antibody before the start of the study and the results are shown in the Table. On serial sections some of the same cells stained in the absorptions with CCK-8, CCK-33 and gastrin at peptide concentrations of $0.00001 \mathrm{~nm}$. Gastrin, however, was much less efficient at absorbing out the antibody activity whereas CCK-8 and CCK-33 were roughly equivalent. Gastrin and $\mathrm{CCK}$ are identical at the last five amino acids at the $\mathrm{C}$-terminal end whereas $\mathrm{CCK}-8$ only consists of the last eight $\mathrm{C}$-terminal amino acids. The results suggest that most of the activity was directed to an antigenic site between amino acids 7 and 8 from the C-terminal end of CCK, but there was some cross reactivity with gastrin. Sections were stored in PBS for up to three days in a $4^{\circ} \mathrm{C}$ cold room before autoradiography was done. Preabsorption with 5HT (Sigma) prevented staining with anti-5HT at a peptide concentration of $0.01 \mathrm{nM}$.

\section{AUTORADIOGRAPHY}

All slides were soaked in $2 \%$ Decon overnight, washed in running water, followed by distilled water, dried and stored in dust free boxes before the sections were cut. Slides were dipped in Ilford $\mathrm{K} 2$ emulsion, the backs were wiped and they were left to dry for two hours. The slides were then sealed in light tight boxes and stored at $4^{\circ} \mathrm{C}$ for 21 days, at the end of which slides were developed with Kodak D19 developer and Amfix fixer. The slides were subsequently stained with Mayer's haematoxylin, dried and mounted with Styrollite. One section from the beginning of the sequence was taken as the control to assess the background for each run of autoradiography. Positive and negative control slides for the emulsion were also included. These were slides which have been covered with emulsion only, one of which had been exposed to light for 10 seconds before the 21 day incubation.

\section{GRAIN COUNTING OF LABELLED NUCLEI}

The background grain count was first established by counting grains over 50 mitoses in a section taken from an animal killed one hour after the first injection for each autoradiography run. The background varied slightly but was of the order of 3-6 grains per nucleus. Any cell nucleus with the background number of grains 


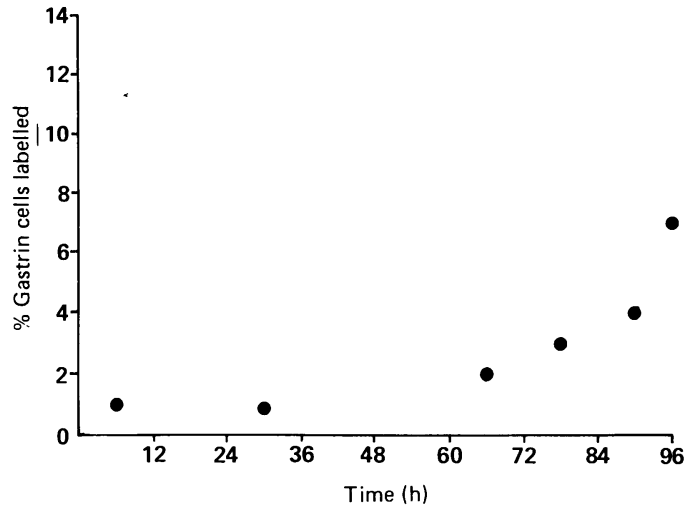

Figure 1: Kinetics of antral gastrin cells (four day study).

or less was counted as negative. One hundred endocrine cells were counted on each slide. Immunochemically positive cells were not counted if the nucleus was out of plane of the section, or if it was unclear to which nucleus the peptide containing cytoplasm belonged. Only obviously immunocytochemically positive cells with definite golden brown granules in a predominantly subnuclear position were counted. Cells with a very heavy overlay of granules over the nucleus were not counted because these could interfere with delineation of the nuclear margin. Grains touching the nuclear membrane were counted even if extending over it. Areas of folding were ignored and only intraepithelial endocrine cells were included.

\section{Results}

FLASH LABELLING EXPERIMENT

In the stomach eight of 500 gastrin cells $1 \cdot 6 \%$ showed flash labelling but only one endocrine cell was flash labelled out of the 600 cells counted in mouse jejunum.

\section{KINETICS OF GASTRIN CELLS IN THE ANTRUM}

In both the four day and eight day kinetic studies there was little labelling of $G$ cells until about 36 hours, with a subsequent slow rise (Figs 1, 2). By eight days labelling had reached levels of 10 $14 \%$. This would give a turnover rate of between 1.7 and $2 \cdot 1 \%$ per day which would indicate a turnover time of between 48 and 59 days.

SMALL INTESTINE

There was no labelling of endocrine cells for the

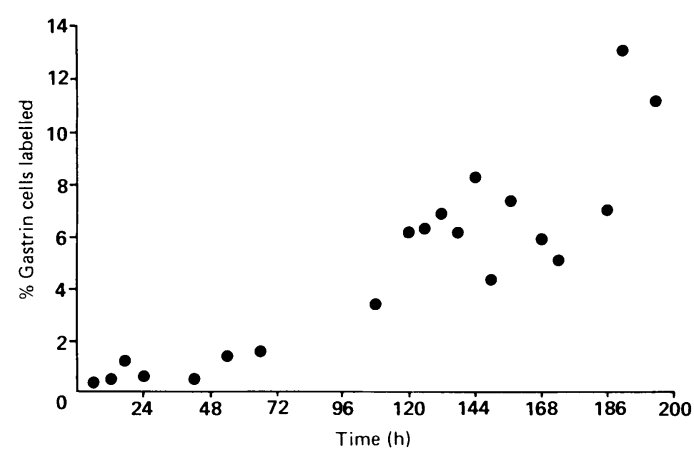

Figure 2: Kinetics of antral gastrin cells (eight day study).

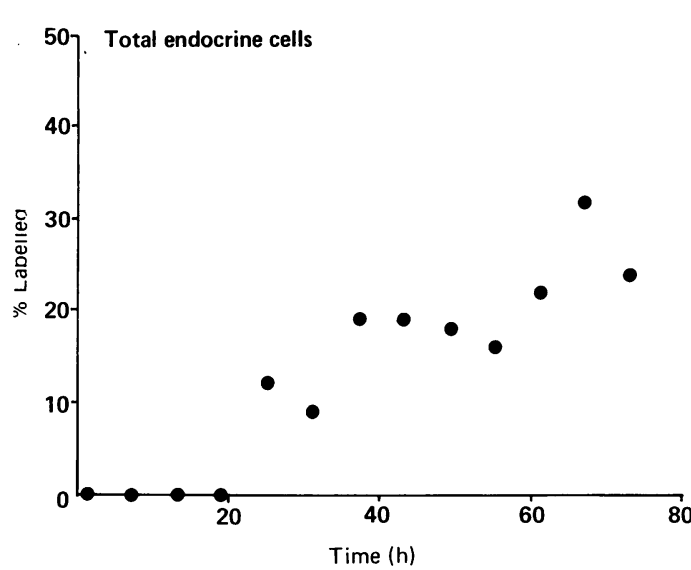

Figure 3: Kinetics of total jejunal cholecystokinin cells from the four day study.

first 24 hours. Thereafter there was a steady increase in labelling until by three days the labelling index for endocrine cells was of the order of $30 \%$ (Fig. 3). Crypt cells labelled ahead of villous cells (Fig. 4) showing labelling indices of $40 \%$ and $20 \%$ by three days respectively, implying migration of the cells up the crypts and onto the villi. No staining could be obtained for anti-5HT antibody in the glutaraldehyde fixed material although gastrin still gave good results. As the four day experiment was clearly too short to look at the kinetics of small intestinal endocrine cells, a longer eight day experiment was performed and this time fixed in Karnovsky's fixative which gave good staining for both 5HT and gastrin.

The results of the eight day kinetic experiment are shown in Figures 5, 6, and 7. There was a low level of labelling (of the order of $5-10 \%$ ) in endocrine cells for the first 24 hours, in contrast with the first experiment. Thereafter the labelling indices increased rapidly to approach $80 \%$ by six and a half days. Again, crypt cells labelled ahead of villous cells (Fig. 6) with very few villous cells labelling before 24 hours. Figure 7 shows the curve for the labelling indices for total jejunal cells, of which the vast majority are columnar enterocytes. Figures 8, 9, 10, and 11 show some examples of autoradiographic labelling in endocrine cells at various stages through the experiment.

From these graphs, the turnover rate (\% cell production per day) and the turnover time (the inverse of the turnover rate) can be calculated. For endocrine cells in the small bowel, the

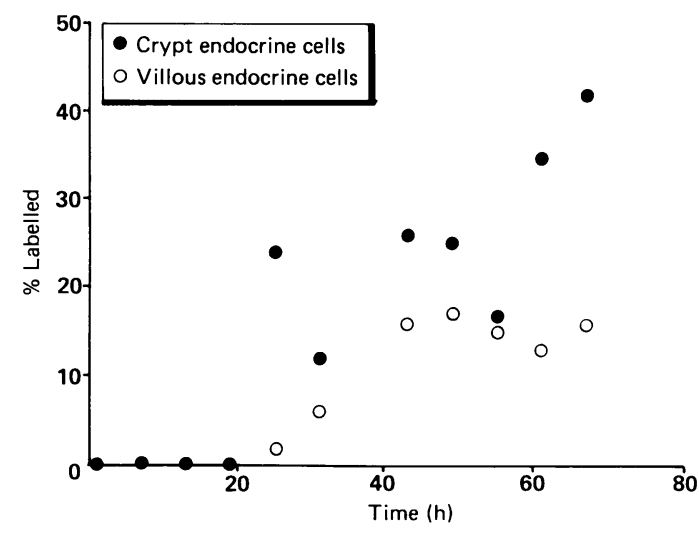

Figure 4: Labelling curves for villous and crypt cholecystokinin cells in the jejunum from the four day study. 




Figure 5: Results for total jejunal endocrine (cholecystokinin) cells in the eight day kinetic study.

results show a turnover rate of $10 \%$ per day and a turnover time of 10 days whereas for columnar cells the figures are $25 \%$ per day and four days respectively.

A series of slides from the eight day experiment were stained with anti-5HT antibody and subsequently underwent autoradiography. As a positive chemography effect was obtained, with most 5HT cells apparently positively labelled even at the beginning of the sequence (Fig. 11), however, only the results for cholecystokinin cells have been presented.

\section{Discussion}

The curves obtained in the four and eight day experiments for gastrin cells in the antrum are similar to those published by Lehy and Willams. ${ }^{9}$ Their flash labelling levels are rather lower, $0 \cdot 3 \%$, as opposed to $1 \cdot 6 \%$. The shapes of the graphs with the sudden rise after 36 hours indicates that gastrin cells are least partially renewed from a stem cell pool. Indeed, the initial labelling may be spurious and it is difficult to differentiate from background at this low level. A turnover time of 45-60 days is slightly shorter than that estimated by Lehy and Willams ${ }^{9}$ which they assessed at two to four months. Hattori and Fujita" found no flash labelling but calculated a half life of 15 days similar to other gastric gland cells with a second population living much longer and migrating more slowly. Our data would not support this. They also found that $2 \%$ of cells lived more than 55 days

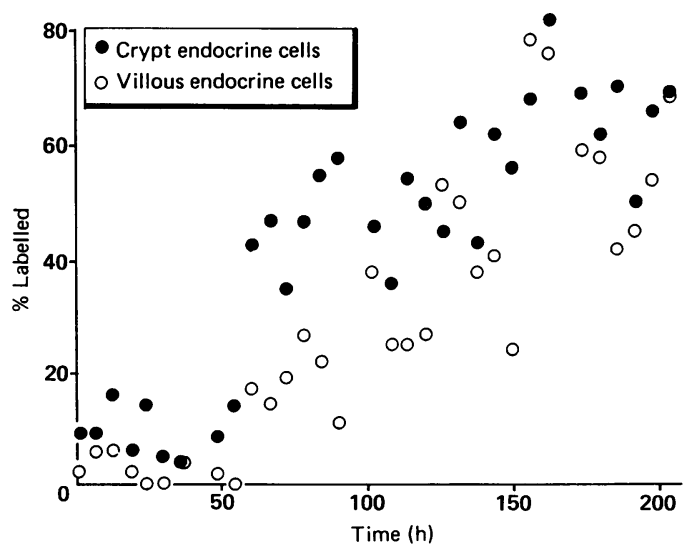

Figure 6: Results for crypt and villous cholecystokinin cells in the jejunum from the eight day study.

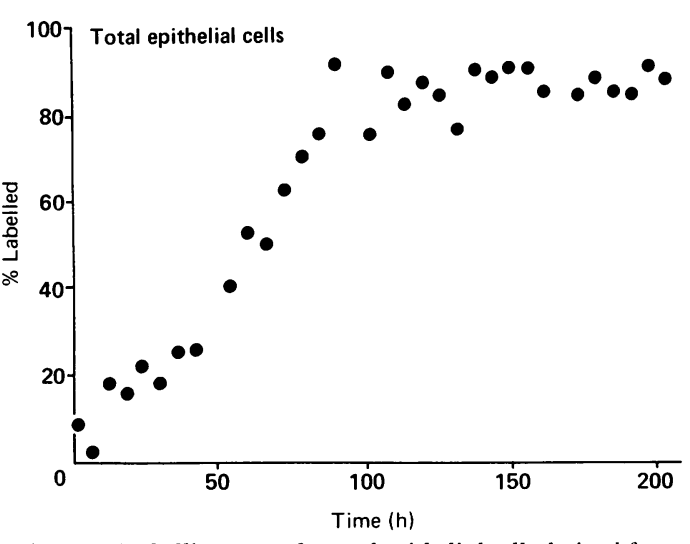

Figure 7: Labelling curve for total epithelial cells derived from the eight day study.

but none were present at 100 days, and they thought that Lehy and Willams's ' estimate was therefore too long. Hattori used a diazo stain to mark endocrine cells, however, and therefore identifying not gastrin cells but argentaffin cells. Also, their work was done on 4-5 $\mu \mathrm{m}$ paraffin embedded sections, which is not ideal as thick sections can prevent tritiated thymidine emissions from reaching the photographic plate giving selfabsorption problems, and also inviting superposition problems.

It would seem, however, that antral gastrin cells have a longer turnover time than endocrine cells in the small bowel, possibly because they are not lost from the villous tip but die in situ in the gastric glands. It would also appear that antral gastrin cells may be capable of limited mitotic activity but it is difficult to assess the relative contributions of the stem cell pool and any proliferative endocrine cell compartments. In addition, in agreement with Lehy and Willams, 9 our data suggest that antral gastrin cell turnover is slower than other gastric gland cells.

The results from the flash labelling experiment and experiment 2 would suggest that there is no mitotic activity in cholecystokinin cells in the small bowel. In experiment 3 the low levels of labelling found in the first 48 hours are at odds with this, but the fact that the slope of the graph for total endocrine cells (Fig. 5) is flat for the first 48 hours might suggest that it may be the result of background noise. When the data are analysed for villous and crypt cells separately (Fig. 6) they

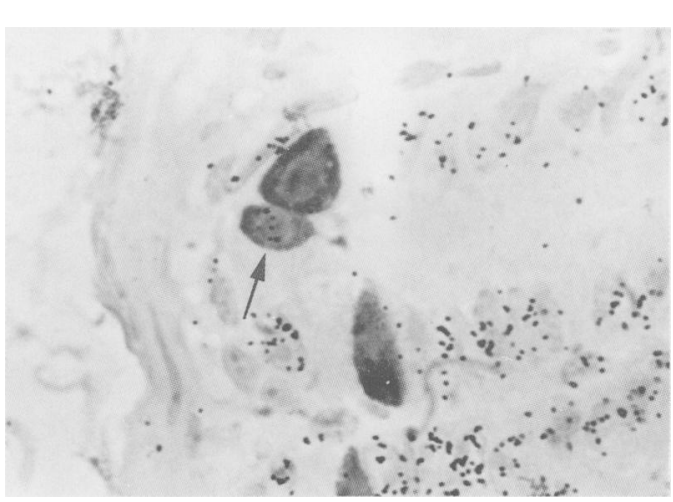

Figure 8: Photomicrograph showing three gastrin cells in the antrum. Although this was from an animal killed at the end of the eight day experiment, only one of the gastrin cell nuclei is labelled (arrowed) in contrast to the other cells in the gland (PAP stain for gastrin, oil immersion). 


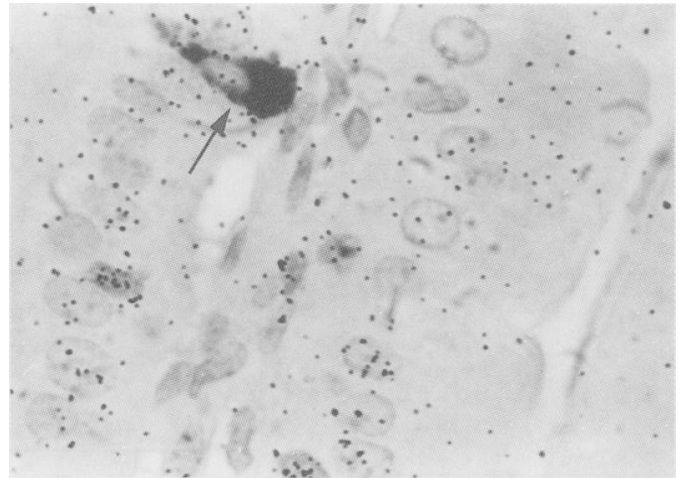

Figure 9: Photomicrograph from the jejunal villus of a mouse killed 60 hours into the eight day kinetic experiment and staining with cholecystokinin antibody. The endocrine cell (arrowed) does not have silver grains over its nucleus but some of the other enterocytes are labelled (PAP stain for cholecystokinin, oil immersion).

could be interpretated as suggesting that the crypt cholecystokinin cells do show mitotic activity. The spread of results is too great, however, to be certain whether this is correct.

The results from the small bowel indicate that jejunal cholecystokinin cells have a turnover time of 10 days, more than twice as long as columnar cells. This is at odds with the result obtained by Cheng and Leblond ${ }^{2+}$ who found the turnover times for columnar, mucous and endocrine cells to be similar. The data presented here, however, are in agreement with these and other authors as to the turnover time for columnar cells, which indicates that the explanation for the difference does not lie in the autoradiographic technique. It may be a result of the way in which endocrine cells have been identified - this current study picks out a specific subpopulation of endocrine cells using an immunocytochemical technique, whereas Cheng and Leblond $^{3}$ identified endocrine cells by their granules. It would seem that different subpopulations may have different turnover rates for example, jejunal cholecystokinin cells and antrum gastrin cells, although this is not a good comparison because of the different migration patterns in these two sites. Another, albeit unlikely, possibility would be that the peptides themselves have a specific effect on the autoradiography. There appeared to be positive chemography effect for 5-hydroxy-cryptomine in the eight-day experiment. The antibodies

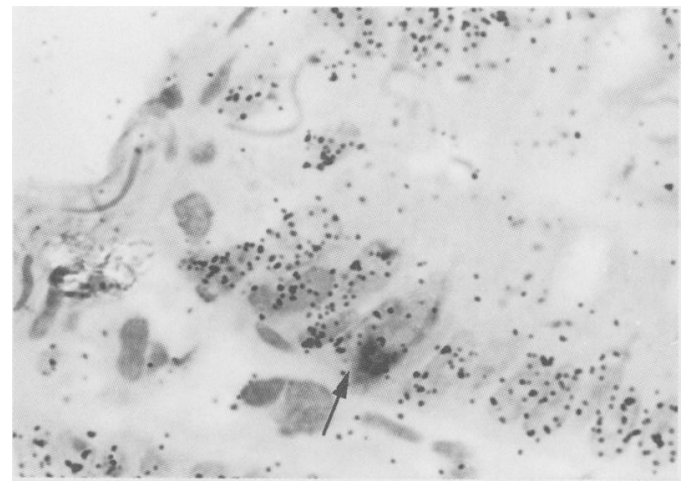

Figure 10: Photomicrograph from the jejunal crypt of a mouse killed at the end of the eight day experiment. Nearly all the cells are labelled including the endocrine cell (arrowed). PAP stain for cholecystokinin, oil immersion).

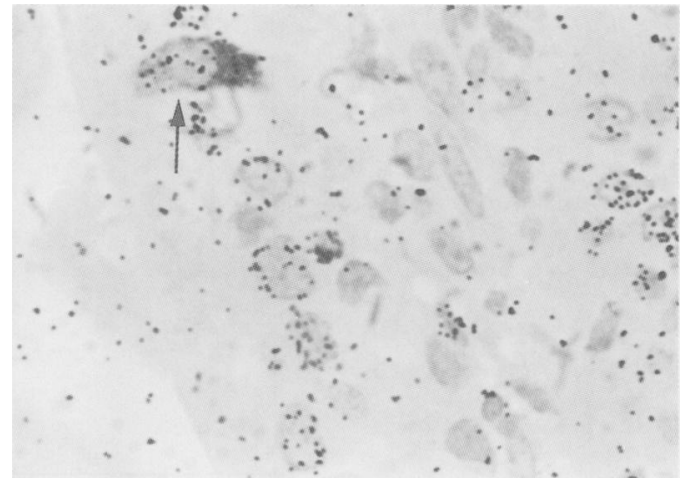

Figure 11: Photomicrograph from the same animal featured in Figure 10 showing that even most villous endocrine cells (arrowed) are labelled by this stage (PAP stain for cholecystokinin, oil immersion).

used to identify gastrin/cholecystokinin and $5 \mathrm{HT}$ are raised in rabbits and the second and third layers used in the PAP technique are identical. In addition, a run for antiglucagon was also done (data not shown) and this did not seem to have a positive chemography effect. Thus, it seems unlikely that the identification of a cell by an antibody per se could result in positive chemography, but perhaps the presence of 5HT peptides and the fixation conditions used may cause a problem. Cheng and Leblond ${ }^{+}$used $2 \cdot 5 \%$ glutaraldehyde for fixation and presumably did not get a false positive chemography effect as they did not find flash labelling in enteroendocrine cells.

In conclusion, it seems likely that the positive chemography effect in 5HT cells was peculiar to the fixation conditions applied in the third kinetic experiment where Karnovsky's fixative was used.

It is interesting that some authors have found evidence for two subpopulations of endocrine cells - those with a rapid turnover and those with a slower one. ${ }^{11-13}$ It may be that the subpopulation that we chose to study is one with a slower turnover.

Cheng and Leblond ${ }^{2-4}$ finding similar turnover characteristics for enteroendocrine cells and other cell types used this to formulate their unitarian hypothesis and support the endodermal stem cell theory. The present data do not support these observations. It there is a multipotential endodermal stem cell giving rise to



Figure 12: Photomicrograph showing spurious labelling of $5 H T$ containing cells on villi of an animal killed six hours into the eight day experiment (PAP for $5 H T$, oil immersion). 
endocrine as well as other enterocyte lineages, there are explanations which could account for the differences in turnover rate. One possibility is that there is a difference in migration rates. The observation of long processes on some endocrine cells, parallel with the basement membrane $^{14}$ could perhaps mean that they are more firmly anchored than other cell types. Another factor which may be relevant could be that enteroendocrine cells have more limited residual proliferative activity than columnar and mucous cells. Cell lineages with greater numbers of cell divisions in the proliferative compartment might be expected to approach $100 \%$ labelling more rapidly than those with very limited capacity for cell division after they had differentiated unless the post stem cell divisions all occurred within a very short time after migrating out of the stem cell compartment.

In any event, the conclusion to be drawn from these data would seem to be that endocrine cells are a kinetically defined cell population or populations, independent of the cell lineages. Such kinetic data can no longer be used to support a common stem cell origin for all cell lineages in gut epithelium, although of course they cannot disprove such a hypothesis.

Dr E M Thompson was supported by the Medical Research Council.
1 Pearse AGE. The diffuse neuroendocrine system and the APUD concept; related 'endocrine' peptides in brain, intestine, pituitary, placenta, and anuran cutaneous gland. Med Biol 1977; 55: 115-25.

2 Cheng $\mathrm{H}$, Leblond CP. Origin, differentiation and renewal of the four main epithelial cell types in the mouse smal intestine. I. Columnar cells. Am F Anat 1974; 141: 461-80.

3 Cheng $\mathrm{H}$, Leblond CP. Origin, differentiation and renewal of the four main epithelial cell types in the mouse small intestine. III. Enteroendocrine cells. Am $\mathcal{F}$ Anat 1974; 141 : 503-20.

4 Cheng $\mathrm{H}$, Leblond CP. Origin, differentiation and renewal of the four main epithelial cell types in the mouse small intestine. $V$. Unitarian theory of the origin of the four epithelial cell types. Am F Anat 1974; 141: 537-62.

5 Odarchenko N, Hedinger C, Ruzicka J, Weber E. Cytokinetics of argentaffin cells in mouse intestinal mucosa Virchows Archiv 1970; 6: 132-6.

6 Inokuchi H, Fujimoto S, Hattori T, Kawai K. Tritiated thymidine radioautographic study on the origin and renewal of secretin cells in the rat duodenum. Gastroenterology 1985 89: 1014-20.

7 Clarke RM. Progress in measuring epithelial turnover in the villi of the small intestine. Digestion 1973; 8: 161-78.

8 Deschner EE, Lipkin $M$. An autoradiographic study of the renewal of argentaffin cells in human rectal mucosa. Exp Cell Res $1966 ; 43$ : 661-5.

9 Lehy T, Willams G. Population kinetics of antral gastrin cells in the mouse. Gastroenterology 1976; 71: 614-9.

10 Tsubouchi S, Leblond CP. Migration and turnover of enteroendocrine and caveolated cells in the epithelium of the descending colon, as shown by radioautography after continuous infusion of ${ }^{3} \mathrm{H}$ thymidine into mice. Am $\mathcal{F}$ Anat 1979 156: 431-51.

11 Hattori T, Fujita S. Tritiated thymidine autoradiographic study of cell migration and renewal in the pyloric mucosa of golden hamsters. Cell Tissue Res 1976; 175: 49-57.

12 Chang WWL, LeBlond CP. Renewal of the epithelium in the descending colon of the mouse. II Renewal of argentaffin cells. Am F Anat 1971; 131: 101-10.

13 Potton CS, Wichmann HE, Leoffler M, Dobek M, Major D. Evidence for discrete cell kinetic subpopulations in mouse Evidence for discrete cell kinetic subpopulations in mouse
epidermis based on mathematical analysis. Cell Tissue Kinet 1982; 15: 305-21.

14 Buchan AMJ, Polak JM. The classification of the human gastroentero-pancreatic endocrine cell. Invest Cell Pathol 1980; 3: 51-71. 